DOI: $10.21767 / 2471-8173.100003$

\title{
Neuroinflammation: Friend or Foe, It's a Matter of Time?
}

Received: September 01, 2015; Accepted: October 10, 2015; Published: October 14, 2015

\section{Mini Review}

Immflamatory cascade was seen historically as detrimental CNS responses to injury that should be suppressed, however it is essential for tissue repair. Intraspinal inflammation caused by trauma persists indefinitely, becoming chronical. Chronical inflammation is detrimental for tissue regeneration. Treatments for spinal cord injury should resolve or modulate neuroinflammation at the appropriate time rather than suppress it completely.

Spinal cord injury $(\mathrm{SCl})$ usually leads to devastating deficits that produce a strong impact on patients, their families and their communities. Neural damage may cause loss of sensory and motor capabilities (paraplegia or tetraplegia), infections, loss of bladder and bowel control, cardiac, sexual and respiratory dysfunctions and the development of neuropathic pain [1-2]. After $\mathrm{SCl}$, primary mechanical insult is followed by the activation of a secondary cascade of events that ultimately causes progressive degeneration of the neural tissue These secondary events include transient permeability of the blood brain barrier (BBB), neuronal and oligodendrocyte death, astrocyte and microglial reactivity, axonal loss, and a robust inflammatory response [3-5]. In this regard, astrocytes, microglial and inflitrating leukocytes (macrophages, neutrophils and lymphocytes) release cytokines, nitric oxide, superoxide anion, eicosanoids and proteases causing neuronal and glial toxicity [6-8] Free radicals, TNFa and IL1b induce apoptosis in neurons and oligondrocytes [9-13]. A feedforward cascade is set in motion whereby this secretory products continue to enhance glial activation and leukocyte migration from the circulation into the CNS. Together, these changes exacerbate neuroinflammation and neurodegeneration. Traditionally inflammation has been considered the primary cause of posttraumatic secondary injury [14-17].

Therefore a number of therapeutic strategies were orientated to suppress inflammation and microglial activation in acute and sub-acute phase after $\mathrm{SCl}$ (ibuprofen, minocycline, methylprednisolone) [18-21]. However, methylprednisolone, a glucocorticoid derivative, reached an extended clinical practice, but re-evaluation and the accumulated expertise have raised serious concerns about its real effectiveness and safety $[22,23]$ and the use of this compound is being reduced in some countries [24]. Thus, generic immune suppressive therapies have been

\section{Labombarda Florencia \\ Department of Human Biochemistry, Buenos Aires University, Argentina}

\author{
Corresponding author: \\ Dr. Labombarda Florencia
}

$\equiv$ luigi.balducci.lb@gmail.com

School of Science, Buenos Aires University, Argentina.

Tel: (++54911) 153-201-0180

Citation: Florencia L. Neuroinflammation: Friend or Foe, It's a Matter of Time?. Spine Res. 2015, 1:1.

largely unsuccessful, mostly because inflammation and immunity exert both beneficial and detrimental effects and these functions change over time. Indeed, controlled acute inflammation and immune invasion are fundamental processes characterizing any wound healing pathway. Neutrophils, have been shown to support recovery [25] by reducing oxidized proteins [26], promoting astrocyte activation and facilitating early production of growth factors [25]. Macrophages, and microglial cells support axonal regeneration $[27,28]$ by clearing growth-inhibitory myelin debris [29], neurotrophic synthesis [30,31], supporting blood vessel formation/ maintenance, and resolving scar deposition [32]. Mononuclear phagocytes and astroctyes, as part of tissue regeneration, also support oligodendrocyte remyelination, as well as oligodendrocyte progenitor cell proliferation (OPC) and differentiation [33-35]. Recently, a pivotal role for recovery was attributed to monocytes that infiltrate the damaged spinal cord due to their nonclassical anti-inflammatory/resolving properties $[36,37]$ These cells enter the traumatized spinal cord through the brain-ventricular choroid plexus, adquire an anti-inflammatory profile, produce the anti-inflammatory cytokine, interleukin 10 (IL-10) and finally terminate the local microglial response $[32,38]$. Several groups have confirmed the therapeutic potential of activated microglia and monocyte derived macrophages in the injured spinal cord [39-41.] Two studies revealed that microglial transplants placed into lesioned spinal cord promoted neurite growth [42]. Although functional recovery was not documented in these latter reports, partial recovery was provided by transplanting activated monocytes into the caudal stump of transected rat spinal cord [41]. Macrophages, activated microglia, and reactive astrocytes within the CNS lesion have a pivotal role in 
the transition between the post injury phase of cleaning the lesion and its preparation for subsequent remodeling, supporting tissue regeneration and extracelular matrix modulation [38]. Therefore, it is essential that inflammation develops in the acute phase of CNS lesion. However it must be controlled by active regulatory mechanisms that lead to the resolution of the inflammatory cascade. The severity of the lesion in part defines the chronicity of the response. The force of the stimuli determines whether inflammation resolves or becomes chronic, also classified as nonresolving inflammation. In this regard, moderate CNS damage evokes protection by microglia and their regulated activation and proper termination might help in tissue preservation, repair, and renewal [43-45]. Conversely intensive acute (SCI) or chronic activation (neurodegenerative diseases) becomes microglial cells neurotoxic and may result in irreversible tissue loss [43,46-48]. Chronic inflammation is a maladaptive response of CNS to the injury and is associated with impaired tissue remodeling [49].

$\mathrm{SCl}$ is an intensive acute injury that develops to a chronic wound. Indeed, intraspinal inflammation caused by trauma persists indefinitely and includes a non self-limiting inflammatory cascade [50-52]. The mechanisms underlying sustained inflammation are not known, but might be due to the inefficient clearance of debris and the failure of BBB repair [38,53]. Consequently, effective repair and wound healing require coordinated inflammation with timely resolution [54].

Since emerge of chordates evolution, bone structures (vertebra column and skull) were selected for CNS protection. Mammal CNS is highly protected and has a low incidence of injuries in nature, thus there was not a strong selection pressure to recovery of severe injuries. On the other hand, if an animal suffer a severe injury the possibility of leaving offspring is minimal. In this evolutionary context there were not several chances to generate an immune system adapted to resolve this kind of severe lesion to the CNS. This coincides with the observation of an immune response that is operative for minor injuries but in the case of major damage seems deregulated generating a chronic inflammation that often increases the damage of the original injury. Inspired by knowledge of natural selection and evolution, we thus suggest that the price of "building a protective wall" was to reduce the probabilities of selecting an immune system which can repair and resolve severe injuries.

Therefore, new therapeutic strategies should be developed based on inflammatory resolution or immunomodulation rather than complete abolishment of inflammation. On one way, scientists should search new resolution agonist, identify anit-resolution factors and develop pro-resolution treatments. In the other way, molecules that moderate inflammation emerges as a good candidates for $\mathrm{SCl}$ treatments, because immune responses in the CNS can have dual effects and global immune suppression is unlikely to yield benefits. In this regard, progesterone, which is widely known by its role in reproduction, emerges as promising candidate for $\mathrm{SCl}$ because the steroid down regulates but not abolish the inflammatory response. Recently we have demonstrated that progesterone treatment after $\mathrm{SCl}$ decrease the expression of pro-inflammatory cytokines (TNF $\alpha$, IL1 $\beta$, IL6), the pro-inflammatory enzymes (iNOS and COX-2) and reactive gliosis by a $50 \%$ compare to injured rats [55] In addition, progesterone after $\mathrm{SCl}$ reduces the extension of secondary injury [56], promotes the differentiation of oligodendrocytes precursor cells into mature oligodendrocytes [57] and improves functional recovery after moderate/severe contusion injury, demonstrated by the improved motor outcome in the BassoBresnahan-Beattie scale for locomotion and CatWalk gait analysis [56]. Progesterone beneficial effects on remyelination was observed 30 days after injury and effects on functional recovery were observed 14 days after injury and were maintained for the duration of the assessment period (60 days), showing long-term benefits. Apparently the merits of progesterone through their immunomodulatory properties lies in turning a "histologically" severe injury into a mild injury, where remyelination and functional recovery are possible.

In conclusion, inflammation is necessary for tissue repair, however if it becomes chronical, regeneration is impaired. Indeed, there is no context in which chronic inflammation is beneficial. Thus treatments for $\mathrm{SCl}$ should help to resolve or modulate neuroinflamation at the appropriate time before its turns detrimental. Thus, everything is a matter of time. 


\section{References}

1 Baptiste D, Fehlings M (2006) Pharmacological approaches to repair the injured spinal cord. Journal of neurotrauma 23: 318-334.

2 Silva N, Sousa N, Reis R, Salgado A (2014) From basics to clinical: a comprehensive review on spinal cord injury. Prog Neurobiol 114 25-57.

3 Ambrozaitis K, Kontautas E, Spakauskas B, Vaitkaitis D (2006) Pathophysiology of acute spinal cord injury. Medicina 42: 255-261.

4 Beattie M, Farooqui A, Bresnahan J (2000) Review of current evidence for apoptosis after spinal cord injury. Journal of neurotrauma 17: 915-925.

5 Borgens R, Liu-Snyder P (2012) Understanding secondary injury. Q Rev Biol 87: 89-127.

6 Bao F, Liu D (2002) Peroxynitrite generated in the rat spinal cord induces neuron death and neurological deficits. Neuroscience 115: 839-849.

7 Chao C, Hu S, Molitor T, Shaskan E, Peterson P (1992) Activated microglia mediate neuronal cell injury via a nitric oxide mechanism. Journal of immunology 149: 2736-2741.

8 Newman T, Woolley S, Hughes P, Sibson N, Anthony D, et al. (2001) T-cell- and macrophage-mediated axon damage in the absence of a CNS-specific immune response: involvement of metalloproteinases. Brain 124: 2203-2214.

9 Hermann G, Rogers R, Bresnahan J, Beattie M (2001) Tumor necrosis factor-alpha induces cFOS and strongly potentiates glutamatemediated cell death in the rat spinal cord. Neurobiology of disease 8: 590-599.

10 Liu B, Gao H, Wang J, Jeohn G, Cooper C, et al. (2002) Role of nitric oxide in inflammation-mediated neurodegeneration. Annals of the New York Academy of Sciences 962: 318-331.

11 Merrill J, Ignarro L, Sherman M, Melinek J, Lane T (1993) Microglial cell cytotoxicity of oligodendrocytes is mediated through nitric oxide. Journal of immunology 15: 2132-2141.

12 Shamash S, Reichert F, Rotshenker S (2002) The cytokine network of Wallerian degeneration: tumor necrosis factor-alpha, interleukin1alpha, and interleukin-1beta. J Neurosci 22: 3052-3060.

13 Xiong Y, Rabchevsky A, Hall E (2007) Role of peroxynitrite in secondary oxidative damage after spinal cord injury. Journal of neurochemistry 100: 639-649.

14 Blight A (1991) Morphometric analysis of a model of spinal cord injury in guinea pigs, with behavioral evidence of delayed secondary pathology. J Neurol Sci 103: 156-171.

15 Dusart I, Schwab M (1994) Secondary cell death and the inflammatory reaction after dorsal hemisection of the rat spinal cord. Eur J Neurosci 6: 712-724.

16 Fleming J, Norenberg M, Ramsay D, Dekaban G, Marcillo A (2006) The cellular inflammatory response in human spinal cords after injury. Brain 129: 3249-3269.

17 Popovich PG (2000) Immunological regulation of neuronal degeneration and regeneration in the injured spinal cord. Prog Brain Res 128: 43-58.

18 Bracken M (1990) Methylprednisolone in the management of acute spinal cord injuries. Med J: 153- 368.

19 Bracken M, Shepard M, Holford T, Leo ST, Aldrich E
Administration of methylprednisolone for $\mathbf{2 4}$ or $\mathbf{4 8}$ hours or tirilazad mesylate for 48 hours in the treatment of acute spinal cord injury. Results of the Third National Acute Spinal Cord Injury Randomized Controlled Trial. National Acute Spinal Cord Injury Study. Jama 277: 1597-1604.

20 Casha S, Zygun D, McGowan M, Bains I, Yong V, et al. (2012) Results of a phase II placebo-controlled randomized trial of minocycline in acute spinal cord injury. Brain 135: 1224-1236.

21 Sharp K, Yee K, Stiles T, Aguilar R, Steward O (2013) A re-assessment of the effects of treatment with a non-steroidal anti-inflammatory (ibuprofen) on promoting axon regeneration via RhoA inhibition after spinal cord injury. Experimental neurology 248: 321-337.

22 Bracken M (2012) Steroids for acute spinal cord injury. Cochrane Database Syst Rev, 1 CD001046.

23 Hurlbert R (2001) The role of steroids in acute spinal cord injury: an evidence-based analysis. Spine 26: S39-46.

24 Schroeder G, Kwon B, Eck J, Savage J, Hsu W, et al. (2014) Survey of cervical spine research society members on the use of high-dose steroids for acute spinal cord injuries. Spine 39: 971-977.

25 Stirling D, Liu S, Kubes P, Yong V (2009) Depletion of Ly6G/Gr-1 leukocytes after spinal cord injury in mice alters wound healing and worsens neurological outcome. J Neurosci 29: 753-764.

26 De Castro D, Hughes M, Xu G, Clifton C, Calingasan N, et al. (2004) Evidence that infiltrating neutrophils do not release reactive oxygen species in the site of spinal cord injury. Experimental neurology 190: 414-424.

27 Lazarov SO, Rapalino O, Agranov G, Schwartz M (1998) Restricted inflammatory reaction in the CNS: a key impediment to axonal regeneration?. Molecular medicine today 4: 337-342.

28 Leon S, Yin Y, Nguyen J, Irwin N, Benowitz L (2000) Lens injury stimulates axon regeneration in the mature rat optic nerve. J Neurosci 20: 4615-4626.

29 Barrette B, Hebert M, Filali M, Lafortune K, Vallieres N, et al. (2008) Requirement of myeloid cells for axon regeneration. J Neurosci 28: 9363-9376.

30 Rolls A, Shechter R, London A, Segev Y, Jacob HJ, et al. (2008) Two faces of chondroitin sulfate proteoglycan in spinal cord repair: a role in microglia/macrophage activation. PLoS medicine 5: e171.

31 Yin Y, Henzl M, Lorber B, Nakazawa T, Thomas T, et al. (2006) Oncomodulin is a macrophage-derived signal for axon regeneration in retinal ganglion cells. Nat Neurosci 9: 843-852.

32 Shechter R, Raposov C, London A, Sagi I, Schwartz M (2011) The glial scar-monocyte interplay: a pivotal resolution phase in spinal cord repair. PloS one 6: e27969.

33 Kokaia Z, Martino G, Schwartz M, Lindvall O (2012) Cross-talk between neural stem cells and immune cells: the key to better brain repair. Nat Neurosci 15: 1078-1087.

34 Kotter M, Setzu A, Sim F, Van RN, Franklin R (2001) Macrophage depletion impairs oligodendrocyte remyelination following lysolecithin-induced demyelination. Glia 35: 204-212.

35 Schonberg D, Goldstein E, Sahinkaya F, Wei P, Popovich P, et al. (2012) Ferritin stimulates oligodendrocyte genesis in the adult spinal cord and can be transferred from macrophages to NG2 cells in vivo. J Neurosci 32: 5374-5384.

36 Kigerl K, Gensel J, Ankeny D, Alexander J, Donnelly D, et al. (2009) 
Identification of two distinct macrophage subsets with divergent effects causing either neurotoxicity or regeneration in the injured mouse spinal cord. J Neurosci 29: 13435-13444.

37 Shechter R, London A, Varol C, Raposo C, Cusimano M, et al. (2009) Infiltrating blood-derived macrophages are vital cells playing an antiinflammatory role in recovery from spinal cord injury in mice. PLoS medicine 6: e1000113.

38 Shechter R, Miller O, Yovel G, Rosenzweig N, London A, et al. (2013) Recruitment of beneficial M2 macrophages to injured spinal cord is orchestrated by remote brain choroid plexus. Immunity 38: 555-569.

39 Bomstein Y, Marder J, Vitner K, Smirnov I, Lisaey G, et al. (2003) Features of skin-coincubated macrophages that promote recovery from spinal cord injury. Journal of neuroimmunology 142: 10-16.

40 Rabchevsky A, Streit W (1997) Grafting of cultured microglial cells into the lesioned spinal cord of adult rats enhances neurite outgrowth. Journal of neuroscience research 47: 34-48.

41 Rapalino O, Lazarov-Spiegler O, Agranov E, Velan G, Yoles E, et al. (1998) Implantation of stimulated homologous macrophages results in partial recovery of paraplegic rats. Nature medicine 4: 814-821.

42 Rabchevsky A, Sullivan P, Scheff S (2007) Temporal-spatial dynamics in oligodendrocyte and glial progenitor cell numbers throughout ventrolateral white matter following contusion spinal cord injury. Glia 55: 831-843.

43 Hanisch U, Kettenmann H (2007) Microglia: active sensor and versatile effector cells in the normal and pathologic brain. Nat Neurosci 10: 1387-1394.

44 Kettenmann H, Hanisch U, Noda M, Verkhratsky A (2011) Physiology of microglia. Physiol Rev 91: 461-553.

45 Ransohoff R, Perry V (2009) Microglial physiology: unique stimuli, specialized responses. Annu Rev Immunol 27: 119-145.

46 Derecki N, Cronk J, Lu Z, Xu E, Abbott S, et al. (2012) Wild-type microglia arrest pathology in a mouse model of Rett syndrome. Nature 484: 105-109.

47 Derecki N, Cronk J, Kipnis J (2013) The role of microglia in brain maintenance: implications for Rett syndrome. Trends Immunol 34 144-150.
48 Scheffel J, Regen T, Van Rossum D, Seifert S, Ribes S, et al. (2012) Tolllike receptor activation reveals developmental reorganization and unmasks responder subsets of microglia. Glia 60: 1930-1943.

49 Serhan C, Savill J (2005) Resolution of inflammation: the beginning programs the end. Nat Immunol 6: 1191-1197.

50 Popovich P, Wei P, Stokes B (1997) Cellular inflammatory response after spinal cord injury in Sprague-Dawley and Lewis rats. The Journal of comparative neurology 377: 443-464.

51 Pruss H, Kopp M, Brommer B, Gatzemeier N, Laginha I, et al. (2011) Non-resolving aspects of acute inflammation after spinal cord injury (SCI): indices and resolution plateau. Brain Pathol 21: 652-660.

52 Rosenberg L, Zai L, Wrathall J (2005) Chronic alterations in the cellular composition of spinal cord white matter following contusion injury. Glia 49: 107-120.

53 Popovich P, Horner P, Mullin B, Stokes B (1996) A quantitative spatial analysis of the blood-spinal cord barrier. I. Permeability changes after experimental spinal contusion injury. Experimental neurology 142: $258-275$

54 Serhan C, Brain S, Buckley C, Gilroy D, Haslett C, et al. (2007) Resolution of inflammation: state of the art. definitions and terms FASEB J 21: 325-332.

55 Labombarda F, Jure I, Gonzalez S, Lima A, Roig P, et al. (2015).A functional progesterone receptor is required for immunomodulation, reduction of reactive gliosis and survival of oligodendrocyte precursors in the injured spinal cord. The Journal of steroid biochemistry and molecular biology.

56 Garcia-Ovejero D, Gonzalez S, Paniagua-Torija B, Lima A, MolinaHolgado E, et al. (2014) Progesterone reduces secondary damage, preserves white matter and improves locomotor outcome after spinal cord contusion. Journal of neurotrauma 31: 857-871.

57 Labombarda F, Gonzalez S, Lima A, Roig P, Guennoun R, et al. (2009) Effects of progesterone on oligodendrocyte progenitors, oligodendrocyte transcription factors and myelin proteins following spinal cord injury. Glia 57: 884-897. 